\title{
Recurrence of COVID-19 with SARS-CoV-2 RNA reversion to positive and late antibody response: a case report from Brazil
}

Fábio de O. Martinez Alonso

Contraprova Diagnósticos, Rio de Janeiro, Brazil

\section{Bruno Duarte Sabino}

Contraprova Diagnósticos, Rio de Janeiro, Brazil

\section{Maria Angelica Arpon Marandino Guimarães}

Departament of Preventive Medicine, University Hospital Clementino Fraga Filho, Federal University of Rio de Janeiro, Brazil. https://orcid.org/0000-0002-5364-7831

Rafael Brandão Varella ( $\nabla$ rvarella@id.uff.br)

Department of Microbiology and Parasitology, Biomedical Institute, Fluminense Federal University, Brazil. https://orcid.org/0000-0002-1698-5989

\section{Case Report}

Keywords: COVID-19, recurrence, SARS-CoV-2, RNA, serology

Posted Date: July 7th, 2020

DOI: https://doi.org/10.21203/rs.3.rs-39990/v1

License: (c) (1) This work is licensed under a Creative Commons Attribution 4.0 International License. Read Full License 


\section{Abstract}

In general, replication of the SARS-CoV-2 in the host reaches its peak in the first week of infection, decreasing rapidly afterwards, while some level of immunity is build up. Yet, the infection seems to follow a distinctive course in some individuals, reactivating after the apparent resolution of symptoms. We report here the first case of a more vigorous COVID-19 recurrence with SARS-CoV-2 RNA reversion to positive and late antibody response, and also the first to address COVID-19 recurrence in Brazil.

\section{Introduction}

Since the first reports on December 2019 up to mid-June 2020, the COVID-19 pandemic caused by the Severe Acute Respiratory Syndrome Coronavirus-2 (SARS-CoV-2), was responsible for hundreds of thousands of deaths [1] and put the world on hold. As the pandemic progresses, the pattern of the infection becomes more predictable, allowing a more concrete decision making in the prevention and control of the disease. However, a still restricted but growing body of publications indicates that certain patients might reactivate a sub-clinical infection or be re-infected [2], showing that much of the viral pathogenesis remains unclear.

\section{Case Presentation}

Figure 1 summarizes the SARS-CoV-2 RNA detection over the patient's clinical history. On 21 April a 26year-old man residing in metropolitan area of Rio de Janeiro, Brazil, without risk factors for COVID-19 reported headache without respiratory symptoms. Two days later, he had respiratory material collected (oropharynx and nasopharynx swabs) for SARS-CoV-2 detection by RT-qPCR using Allplex ${ }^{\text {TM }} 2019$-nCoV Assay (Seegene Inc., Seoul, Korea), which targets the RNA-dependent RNA polymerase (RdRP), N genes specific for SARS-CoV-2, and E genes for all Sarbecovirus, including SARS-CoV-2. The cycle threshold (Ct) values from the qRT-PCR were measured; $C t$ values $<40$ were reported as positive. The sample tested positive for SARS-CoV-2 RNA (E Ct: 31.5; RdRp Ct: 34.1; N Ct: 31.5).

Being a mild infection, the patient remained in isolation for 14 days at home, recovering after 7 days of symptoms onset. On 5 May, after a new respiratory swab collection, the viral RNA was no longer detected. IgM/IgA and IgG antibodies were negative by COVID-19 ELISA test (Vircell, Spain). However, one month later, on 6 June, the symptoms returned more acutely and included fever, cough, headache, myalgia, arthralgia, anosmia and fatigue, and lasted for almost two weeks. SARS-CoV-2 RNA detection reversed to positive (E Ct: 19.9; RdRp Ct: 20.8; N Ct: 22.7) on 8 June and remained positive in another testing on 16 June (E Ct: 32.8; RdRp Ct: 33.4; N Ct: 34.5), although SARS-CoV-2 antibodies remained negative. Chest CT scan performed on 18 June showed typical findings of multiple patchy ground-glass opacities (GGO) in lungs (Figure 2). 
During this second episode of COVID-19, the patient was treated on an outpatient basis with azithromycin plus analgesics and antipyretics for six days when symptoms subsided. Finally, on 22 June, $\lg \mathrm{A} / \operatorname{lgM}$ and IgG antibodies were detected in serum and only $\mathrm{N}$ gene was detected by RT-qPCR (Ct: 36.6). SARS-CoV-2 viremia was also investigated after recurrence in plasma samples collected on 8 and 16 June, showing negative results.

\section{Discussion}

Different reports indicate that reactivation or re-infection by SARS-CoV-2 are possible, although the event appears to be unusual [3]. Such "reversal to positivity" after negative molecular tests may be due to methodological issues such as sample storage problems, poorly performed sample collection, etc., pointing towards false-negative results [4]. However, such reactivation also has a biological basis [3].

In this case, the virus could still replicate in undetectable levels in nasopharynx and maybe in the lower respiratory tract [5] during convalescence, regaining full replication after some time, probably driven by the host's immune status [6]. On the other hand, a re-infection with a new or maybe the same circulating strain is not unfeasible [3], given the different profiles of immune response to the virus [7]. In fact, the detection of SARS-Cov-2 RNA with the absence of anti-SARS-CoV-2 antibody response has been previously observed [8].

Although cases vary in terms of serological data, timing of reactivation and clinics, patients who retested positive to SARS-CoV-2 generally have a mild or asymptomatic course [9-13], which is perhaps the result of some level of immunity, while symptomatic reactivation is rare but may happen [14]. Our patient, on the other hand, presented a more potent form of COVID-19 after more than 40 days from the first mild infection, and with a detectable antibody response only after the second infectious episode. Our hypothesis is that the first mild infection was not sufficient to build up a detectable humoral response [8], which occurred only after 14 days of a second more severe episode. In addition, the absence of detectable antibodies in the first episode may have allowed for a new infection, rather than a recurrence. However, as we did not investigate viral genetics at different times, such a statement is hypothetical.

A limitation of this study is due to the absence of cell culture assays during the period, which could indicate the presence of infectious particles. Also, a false-positive result in the first RT-qPCR test cannot be ruled out as well, so that the patient only became infected with SARS-CoV-2 afterwards, instead of its "reactivation". However, given the 1) high specificity of RT-qPCR test; 2) presentation of symptoms coinciding with the positive RT-qPCR; and 3) viral detection in close family members living in the same residence during COVID-19 symptoms (data not shown); such false result is unlikely.

In this paper, we describe a COVID-19 recurrence from a mild to a moderate form after convalescence, with RT-qPCR turning positive and antibody detection after more severe symptoms. These findings, although summarized in a case report, raise questions about the influence of the severity of the infection on the immune response and the host's susceptibility, which can have important epidemiological consequences, and should be better understood. 


\section{Declarations}

\section{Funding}

This paper was supported by Laboratório Contraprova Análises, Ensino e Pesquisas LTDA. Varella RB. was partially supported by National Council for Scientific and Technological Development - CNPq.

\section{Conflicts of interest/Competing interests}

The authors declare no conflicts of interest

\section{Data availability}

All available information is contained within the manuscript.

\section{Ethical approval}

The study was approved by the University Hospital Ethical Committee of the Fluminense Federal University (register 30926020.2.0000.5243).

\section{Consent for publication}

Written informed consent was obtained from the patient for publication of this case and any accompanying images.

\section{Author contributions}

All authors contributed to the study conception and design. Data collection and laboratorial analysis were performed by FA and BS. The first draft of the manuscript was written by RV and MAG and all authors commented on previous versions of the manuscript. All authors read and approved the final manuscript.

\section{References}

1. World Health Organization. Coronavirus disease (COVID-19) outbreak situation. https://www.who.int/emergencies/diseases/novel-coronavirus-2019/situation-reports/ (accessed 16 June 2020).

2. Hoang VT, Dao TL, Gautret P. Recurrence of positive SARS-CoV-2 in patients recovered from COVID19. J Med Virol 2020; https://doi.org/10.1002/jmv.26056. doi:10.1002/jmv.26056.

3. Kang, H, Wang, Y, Tong, Z, Liu, X. Retest positive for SARS-CoV-2 RNA of "recovered" patients with COVID-19: Persistence, sampling issues, or re-infection? J Med Virol 2020; https://doi.org/10.1002/jmv.26114.

4. Xiao AT, Tong YX, Zhang S. False-negative of RT-PCR and prolonged nucleic acid conversion in COVID-19: Rather than recurrence. J Med Virol 2020; https://doi.org/10.1002/jmv.25855. 
5. Chen D, Xu W, Lei Z, et al. Recurrence of positive SARS-CoV-2 RNA in COVID-19: A case report. Int J Infect Dis 2020;93:297-299. https://doi.org/10.1016/j.jijid.2020.03.003.

6. Ye G, Pan Z, Pan Y, et al. Clinical characteristics of severe acute respiratory syndrome coronavirus 2 reactivation. J Infect 2020;80(5):e14-e17; https://doi.org/10.1016/j.jinf.2020.03.001.

7. Long, Q., Liu, B., Deng, H. et al. Antibody responses to SARS-CoV-2 in patients with COVID-19. Nat Med 2020; https://doi.org/10.1038/s41591-020-0897-1.

8. Lin YC, Cheng CY, Chen CP, Cheng SH, Chang SY, Hsueh PR. A case of transient existence of SARSCoV-2 RNA in the respiratory tract with the absence of anti-SARS-CoV-2 antibody response. Int $J$ Infect Dis 2020;96:464-466; https://doi.org/10.1016/j.ijid.2020.05.070.

9. Lan L, Xu D, Ye G, et al. Positive RT-PCR Test Results in Patients Recovered From COVID-19. JAMA 2020;323(15):1502-1503; https://doi.org/10.1001/jama.2020.2783.

10. Cao H, Ruan L, Liu J, Liao W. The clinical characteristic of eight patients of COVID-19 with positive RT-PCR test after discharge. J Med Virol 2020; https://doi.org/10.1002/jmv.26017. doi:10.1002/jmv.26017.

11. Yuan J, Kou S, Liang Y, Zeng J, Pan Y, Liu L. PCR Assays Turned Positive in 25 Discharged COVID-19 Patients. Clin Infect Dis. 2020; https://doi.org/10.1093/cid/ciaa398.

12. Jiang $M$, Li Y, Han M, Wang Z, Zhang Y, Du X. Recurrent PCR positivity after hospital discharge of people with coronavirus disease 2019 (COVID-19). J Infect 2020;81(1):147-178. https://doi.org/10.1016/j.jinf.2020.03.024.

13. Fu, W., Chen, Q. and Wang, T. Letter to the Editor: Three cases of redetectable positive SARS-CoV-2 RNA in recovered COVID-19 patients with antibodies. J Med Virol 2020 https://doi.org/1002/jmv.25968.

14. Loconsole D, Passerini F, Palmieri VO, et al. Recurrence of COVID-19 after recovery: a case report from Italy. Infection 2020;1-3; https://doi.org/10.1007/s15010-020-01444-1.

\section{Figures}




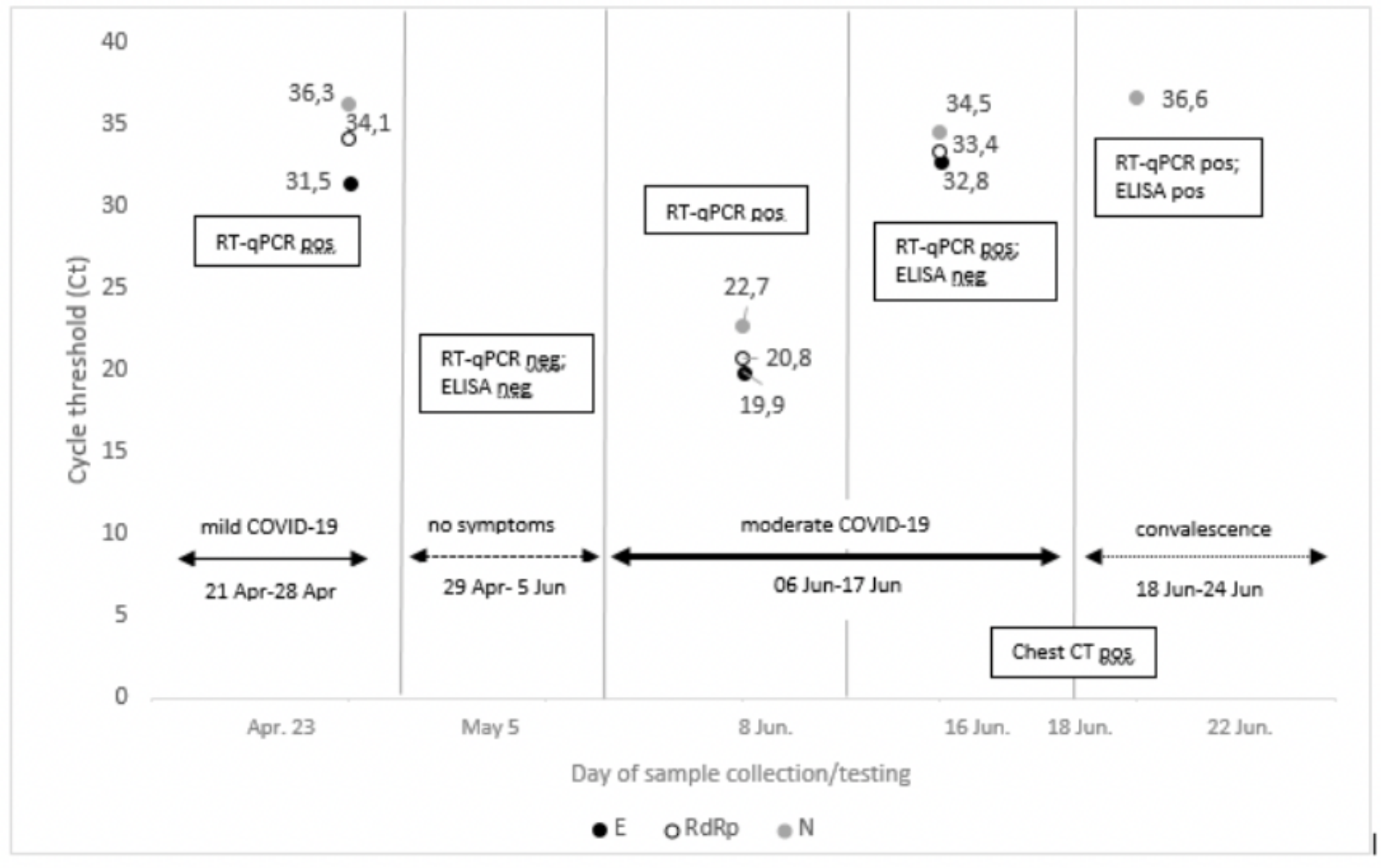

Figure 1

Dynamics of RT-qPCR cycle threshold (Ct) of SARS-CoV-2 genes E, RdRp and N throughout the clinical history of the patient. RT-qPCR pos: SARS-CoV-2 RNA detection; ELISA pos: IgA/IgG and IgG detection; Chest CT pos: presence GGO in lungs.

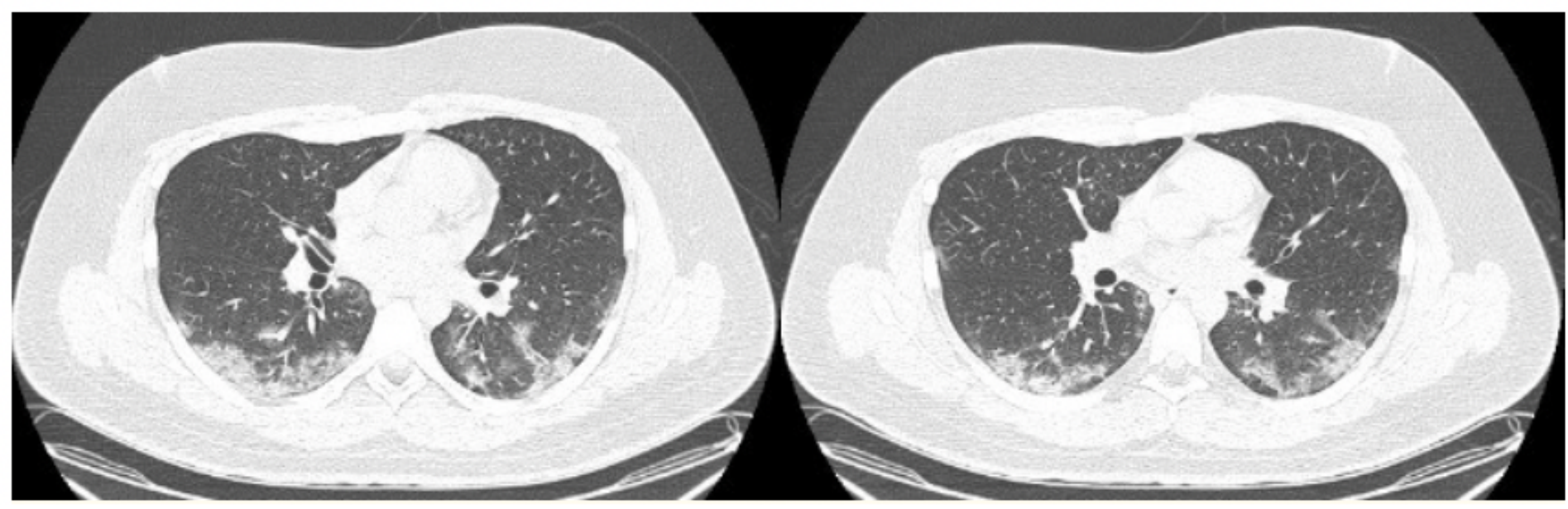

Figure 2

Chest CT images of the patient showing multiple patchy ground glass opacities. 